\section{A note on occurrence of Ehrlichia infection in a Langur (Semnopithecus sp.) from Nagpur, Maharashtra, India}

\section{B.S. Baviskar ${ }^{1}$, P.J. Gawande ${ }^{2}$, A.K. Jayraw ${ }^{3}$, D.K. Maske ${ }^{4}$ \& S.S. Raut ${ }^{5}$}

1,2,4,5 Department of Parasitology, Nagpur Veterinary College, Maharashtra Animal and Fishery Sciences University, Seminary Hills, Nagpur, Maharashtra 440006, India

Department of Parasitology, Bombay Veterinary College, Parel, Mumbai, Maharashtra 400 012, India

E-mail: ${ }^{1}$ drbaharbaviskar@ rediffmail.com; ${ }^{2}$

drpriyagawande@gmail.com; ${ }^{3}$ jayrawanant1 @ rediffmail.com;

${ }_{4}^{4}$ jayrawanant1 @ rediffmail.com (Corresponding author)

Ixodid tick transmitted ehrlichiosis has a broad host range that includes humans, domestic animals and wild animals such as Deer (Belongia et al. 1997), Lions (Buoro et al. 1994), Lemurs (Williams et al. 2002), Rhesus Macaques (Lewis et al. 1975) and Baboons (Lewis et al. 1975). Although the disease has been recorded in nonhuman primates from other parts of the globe, information is lacking from Indian subcontinent. Langurs are distributed from the Himalaya to Cape Comorin with the exception of the western deserts (Prater 1990), and they may act as a blood reservoir by infecting ticks for subsequent transmission to other mammals. The present communication reports the occurrence of Ehrlichia infection in a langur (Semnopithecus sp.) from Nagpur District of Maharashtra State.

A severely injured and anaemic langur from Nagpur was presented for treatment at Nagpur Veterinary College Hospital, Nagpur. Clinical and radiological examination revealed fracture in a forelimb, which was removed surgically. The animal did not survive and succumbed to its injuries. A post-mortem examination was performed within an hour after death and blood smears were prepared from heart blood, stained with Leishman's stain and examined under a microscope. Identification was performed based on morphological characters (Kreier 1977).

Ehrlichiosis is well known as an important emerging tick-

Date of publication (online): 26 August 2009

Date of publication (print): 26 August 2009

ISSN 0974-7907 (online) | 0974-7893 (print)

Editor: Jacob V. Cheeran

\section{Manuscript details:}

Ms \# 01777

Received 14 May 2007

Final received 09 September 2008

Finally accepted 15 June 2009

Citation: Baviskar, B.S., P.J. Gawande, A.K. Jayraw, D.K. Maske \& S.S. Raut (2009). A note on occurrence of Ehrlichia infection in a Langur (Semnopithecus sp.) from Nagpur, Maharashtra, India. Journal of Threatened Taxa 1(8): 444.

Copyright: (c) B.S. Baviskar, P.J. Gawande, A.K. Jayraw, D.K.Maske and S.S. Raut 2009. Creative Commons Attribution 3.0 Unported License. JoTT allows unrestricted use of this article in any medium for non-profit purposes, reproduction and distribution by providing adequate credit to the authors and the source of publication.

Acknowledgement: The authors are thankful to the Associate Dean, Nagpur Veterinary College, Maharashtra Animal and Fishery Sciences University, Nagpur for providing necessary facilities. borne disease of mammals having a broad host range. Detection of Ehrlichia organisms in monocytes of a nonhuman primate, the langur, seems to be a first report from Indian subcontinent. The occurrence of disease has been well-documented in human and nonhuman primates from other parts of the globe. Foley et al. (1999) successfully inoculated two Rhesus Macaques (Macaca mulatta) with human granulocytic ehrlichiosis, which was confirmed by polymerase chain reaction (PCR), Western blot and clinical manifestations. Natural Ehrlichia chaffeensis infection in 2 prosimian primate species i.e. Ring-tailed Lemur (Lemur catta) and Ruffed Lemur (Varecia variegata) was documented by Williams et al. (2002) from Duke University Primate Center (U.S.A.). Ring-tailed Lemurs, Blue-eyed Black Lemurs (Eulemur macaco flavifrons) and Black and White Ruffed Lemurs (Varecia variegata variegata) were tested serologically and by PCR assay for detection of tick-borne ehrlichiae and were found positive without showing any clinical manifestations (Yabsley et al. 2004). Rhesus Macaques and Baboons (Papio anubis) were inoculated with Ehrlichia equi, the etiologic agent of equine ehrlichiosis and ehrlichial morulae were evidenced in neutrophils of Rhesus Macaques and Baboons (Lewis et al. 1975). E. chaffeensi and a Venezuelan human Ehrlichia, likely a strain of E. canis, has been isolated from a human (Anderson et al., 1991; Perez et al., 1996). However, inoculation of E. canis by Van Harden and Goosen (1981) did not induce disease in vervet monkeys (Cercopithecus pygerythrus).

\section{References}

Anderson, B.E., J.E. Dawson, D.C. Jones \& K.H. Wilson (1991). Ehrlichia chaffeensis, a new species associated with human ehrlichiosis. Journal of Clinical Microbiology 29: 2838-2842.

Belongia, E., K. Reed, P. Mitchell, C. Kolbert, D. Persing, J. Gill \& J. Kazmierczak (1997). Prevalence of granulocytic Ehrlichia infection among white-tailed deer in Wisconsin. Journal of Clinical Microbiology 35: 1465-1468.

Buoro, I.B.J., S.B. Nyamwange \& J.C. Kiptoon (1994). Presence of Ehrlichia-like bodies in monocytes of adult lioness. Feline Practice 22(1): 36-37

Foley, J.E., N.W. Lerche, J.S. Dumler \& J.E. Madigan (1999). A simian model of human granulocytic ehrlichiosis. American Journal of Tropical Medicine and Hygiene 60(6): 987-993.

Kreier, J. P. (1977). Parasitic Protozoans, Vol. IV. Academic Press, London.

Lewis, G.E., D.L. Huxsoll, M. Ristic \& A.J. Johnson (1975). Experimentally induced infection of dogs, cats and nonhuman primates with Ehrlichia equi, etiologic agent of equine ehrlichiosis. American Journal of Veterinary Research 36(1): 85-88.

Perez, M., Y. Rikihisa \& B. Wen (1996). Ehrlichia canis-like agent isolated from a man in Venezuela: antigenic and genetic characterization. Journal of Clinical Microbiology 34: 2133-2139.

Prater, S.H. (1990). The Book of Indian Animals. $3^{\text {rd }}$ edition. Oxford University Press, Bombay, 39pp

Van Heerden, J. \& D.J. Goosen (1981). Attempted transmission of canine ehrlichiosis to the vervet monkey (Cercopithecus pygerythrus). Onderstepoort Journal of Veterinary Research 48(2): 127-128.

Williams, C.V., J.L.V. Steenhouse, J.M. Bradley, S.I. Hancock, B.C. Hegarty \& E.B. Breitschwerdt (2002). Naturally occurring Ehrlichia chaffeensis infection in two prosimian primate species: ring tailed lemurs (Lemur catta) and ruffed lemurs (Varecia variegata). Emerging. Infectious Diseases 8(12): 1497-1500.

Yabsley, M.J., T.M. Norton, M.R. Powell \& W.R. Davidson (2004). Molecular and serologic evidence of tick-borne ehrlichiae in three species of lemurs from St. Catherines Island, Georgia, USA. Journal of Zoo and wildlife Medicine 35(4): 503-509. 